\title{
PENGARUH KEMAMPUAN, PENGALAMAN DAN DISIPLIN KERJA TERHADAP KINERJA KARYAWAN
}

\author{
Eza Herlambang Taufik \\ E-mail: Ezaherlambang@gmail.com \\ Muhammad Harlie \\ Kurniaty
}

Universitas Islam Kalimantan (UNISKA) MAB Banjarmasin

\begin{abstract}
The evolution of the forex market is divided into two stages. World War IPeriod and the Bretton Woods period is included Fixed Rate Periodstage. At this stage, forex does not excite transactions because of exchange rate changes can only occur in a relatively narrow range. After a period of Bretton Woods, after the failure of Period Exchange Rates Remain in maintaining economic stability, forex transactions getting psyched. This occurs because the assessment of the exchange rate between countries be left entirely to the market mechanism. The market will determine whether the exchange rate is too expensive (over-valued) or too low (under-valued).

This study aims to determine the effect of ability, experience and discipline together and partially on the performance forex trader in South Kalimantan. This type of research is quantitative method. The samples were obtained 56 votes. To determine the effect the ability, experience and discipline to the performance of the test statistic methods trader used multiple linear regression. Data processing was performed using IBM SPSS Statistics 23 program for Windows.

Based on the results of the research show that together the ability, experience and discipline significant effect on the performance of forex traders in South Kalimantan. Partially, ability, experience and discipline positive and significant impact on the performance of forex traders in South Kalimantan.
\end{abstract}

Keywords: Capability, Experience, Discipline and Performance 


\section{PENDAHULUAN}

Dalam era globalisasi dan
perdagangan bebas yang
semakinberkembang pesat dan
menuju kepersaingan ekonomi yang
semakinkompeten dengan

kecanggihan tekhnologi yang semakin hari semakinberkembang pesat akan menyaingi kemampuan manusia, menuntutmanusia agar berpikir dan berusaha dengan selalu berkompetensi dan bersaing dengan yang lainnya, karena jika tidak, maka akan ketinggalanjauh dengan yang lain, baik dari segi pemikiran, informasi maupun dalambidang ekonomi. Forex Trading atau FX Trading (kependekan dari Foreign Exchangeatau pertukaran Valuta Asing-Valas) merupakan perdagangan mata uangkedua negara yang nilainya berbeda dari waktu kewaktu.

Beberapa penelitian tentang forex trading telah dilakukan dengan hasil yang berbeda maka mengakibatkan adanya research gap. Selain research gap, masalah yang terjadi di kalimantan selatan adalah masih banyaknyatrader yang belum mendapatkan profit secara maksimal. Penulis telah melakukan wawancara lewat sosial media kepada beberapa trader di kalimantan selatan dan mendapatkan data bahwa dari 20 trader terdapat 12 orang yang masih mengalami margin call pada tahun 2015. Berkaitan dengan permasalahan di atas maka peneliti melakukan penelitian dengan judul "Pengaruh Kemampuan, Pengalaman dan Disiplin Terhadap Kinerja (Studi Pada Foreign Exchange Trader Di Kalimantan Selatan)"dengan harapan akan membantu meningkatkan kualitas SDM di Kalimantan Selatan sehingga dampaknya akan mengurangi tingkat pengangguran dan meningkatkan taraf hidup masyarakat dengan berinvestasi menggunakan cara yang tepat.

\section{TINJAUAN PUSTAKA}

Pengertian Pengalaman Kerja terdiri dari beberapa macam yang diberikan oleh para ahli. 
Pengalaman dalam semua kegiatan sangat diperlukan, karena experience is the best teacher, pengalaman guru yang terbaik. Maksud dari hal tersebut adalah bahwa seseorang belajar dari pengalaman yang pernah dialaminya. Menurut Kamus Bahasa Indonesia (Depdiknas, 2005), "pengalaman dapat diartikan sebagai yang pernah dialami (dijalani, dirasa, ditanggung, dsb)".

Elaine B Johnson (2007) menyatakan bahwa "pengalaman memunculkan potensi seseorang. Potensi penuh akan muncul bertahap seiring berjalannya waktu sebagai tanggapan terhadap bermacam-macam pengalaman". Jadi sesungguhnya yang penting diperhatikan dalam hubungan tersebut adalah kemampuan seseorang untuk belajar dari pengalamannya, baik pegalaman manis maupun pahit. Maka pada hakikatnya pengalaman adalah pemahaman terhadap sesuatu yang dihayati dan dengan penghayatan serta mengalami sesuatu tersebut diperoleh pengalaman, ketrampilan ataupun nilai yang menyatu pada potensi diri.

Lingkungan kerja adalah kehidupan sosial, psikologi, dan fisik dalam perusahaan yang berpengaruh terhadap pekerja dalam melaksanakan tugasnya. Kehidupan manusia tidak terlepas dari berbagai keadaan lingkungan sekitarnya, antara manusia dan lingkungan terdapat hubungan yang sangat erat. Dalam hal ini, manusia akan selalu berusaha untuk beradaptasi dengan berbagai keadaan lingkungan sekitarnya. Demikian pula halnya ketika melakukan pekerjaan, karyawan sebagai manusia tidak dapat dipisahkan dari berbagai keadaan disekitar tempat mereka bekerja, yaitu lingkungan kerja. Selama melakukan pekerjaan, setiap pegawai akan berinteraksi dengan berbagai kondisi yang terdapat dalam lingkungan kerja.

Pengertian Kinerja : Kinerja seorang karyawan merupakan hal yang 
bersifat individual, karena setiap karyawan mempunyai tingkat kemampuan yang berbeda - beda dalam mengerjakan tugasnya. Pihak manajemen dapat mengukur karyawan atas unjuk kerjanya berdasarkan kinerja dari masing masing karyawan. Kinerja adalah sebuah aksi, bukan kejadian. Aksi kinerja itu sendiri terdiri dari banyak komponen dan bukan merupakan hasil yang dapat dilihat pada saat itu juga. Pada dasarnya kinerja merupakan sesuatu hal yang bersifat individual, karena setiap karyawan memiliki tingkat kemampuan yang berbeda dalam mengerjakan tugasnya.

\section{Kerangka Konsep}

Berdasarkan teori pada penelitian, maka dapat disusun suatu kerangka pemikiran sebagai berikut:

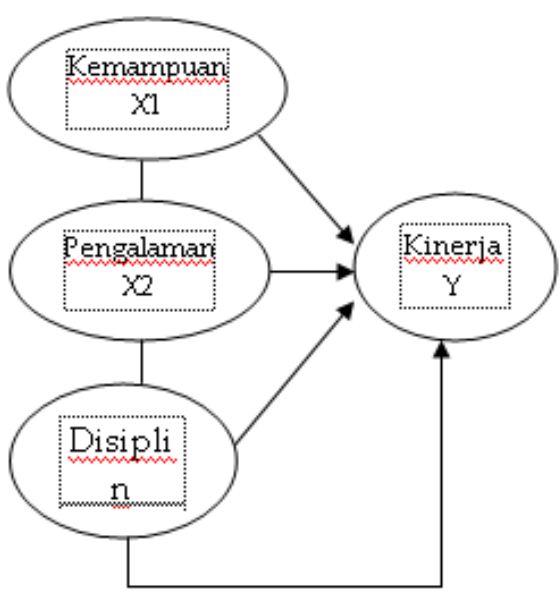

Keterangan :

$$
\begin{aligned}
& \longrightarrow \text { : Variabel yang diteliti } \\
& \text { Gambar 3.1 Kerangka Pemikiran }
\end{aligned}
$$

\section{Hipotesis}

Penelitian yang merumuskan hipotesis adalah penelitian yang menggunakan pendekatan kuantitatif. Pada penelitian kualitatif, tidak dirumuskan hipotesis, tetapi justru diharapkan dapat ditemukan hipotesis. Selanjutnya hipotesis tersebut akan diuji oleh peneliti dengan menggunakan pendekatan kuantitatif.

Berdasarkan landasan teori, dan kerangka konseptual diatas, maka hipotesis yang dikemukakan adalah 
$\mathrm{H}_{1}$ : Kemampuan berpengaruh signifikan terhadap kinerja foreign exchangetrader di Kalimantan Selatan.

$\mathrm{H}_{2}$ : Pengalaman berpengaruh signifikan terhadap kinerja foreign exchangetrader di Kalimantan Selatan.

$\mathrm{H}_{3}$ : Disiplin berpengaruh signifikan terhadap kinerja foreign exchangetrader di Kalimantan Selatan.

$\mathrm{H}_{4}$ : Kemampuan, Pengalaman dan Disiplin secara simultan berpengaruh signifikan terhadap kinerja foreign exchangetrader di Kalimantan Selatan.

\section{METODE PENELITIAN}

Metode penelitian adalah suatu cara memperoleh atau mengumpulkan data, baik berupa data primer maupun data sekunder yang digunakan untuk keperluan menyusun suatu karya ilmiah dan kemudian menganalisa faktor-faktor yang berhubungan dengan penelitian tersebut.
Metode Pengukuran data pada penelitian ini menggunakan metode skala likert. Dengan penggunaan skala likert ini responden dihadapkan pada pertanyaan dan kemudian diminta untuk memberikan jawaban yang dianggap paling sesuai. Alternatif penilaian dalam pengukuran itemitem tersebut terdiri dari 5 (lima) alternatif pilihan yang mempunyai gradasi sangat positif sampai dengan sangat negatif.

\section{HASIL DAN PEMBAHASAN}

Analisis regresi linier berganda digunakan untuk menguji hipotesis pengaruh secara simultan dan parsial antara variabel independen terhadap dependen. Berdasarkan estimasi regresi linier berganda dengan menggunakan program IBM SPSS Statistics Versi 23, maka diperoleh hasil seperti tabel dibawah ini :

Tabel 5.13Analisis Regresi Linier Berganda 


\begin{tabular}{|l|c|r|r|r|}
\hline \multicolumn{7}{|c|}{ Model Summary } \\
\hline Model & R & R Square & $\begin{array}{c}\text { Adjusted R } \\
\text { Square }\end{array}$ & $\begin{array}{r}\text { Std. Error of } \\
\text { the Estimate }\end{array}$ \\
\hline 1 &, 893 &, 797 &, 785 & 2,377 \\
\hline
\end{tabular}

Sumber: data primer diolah, 2016

Dari hasil diatas diketahui bahwa nilai $\mathrm{R}$ adalah 0,893 , yang berarti ada pengaruh positif dari variabel kemampuan, pengalaman dan disiplin terhadap kinerja. Sedangkan nilai $\mathrm{R}$ Square adalah 0,797 . Untuk mengetahui besarnya pengaruh variabel kemampuan, pengalaman dan disiplin terhadap kinerja secara simultan dengan cara menghitung Koefisien Determinan (KD) dengan rumus sebagai berikut :

$$
\begin{aligned}
\mathrm{KD} & =\mathrm{R}^{2} \times 100 \% \\
& =0,797 \times 100 \% \\
& =79,7 \%
\end{aligned}
$$

Hal ini menunjukkan bahwa pengaruh variabel kemampuan, pengalaman dan disiplin terhadap kinerja secara simultan sebanyak $79,7 \%$, sedangkan $20,3 \%$ dipengaruhi oleh faktor lainnya.

$$
\text { Untuk menguji Hipotesis }
$$
maka dilakukan lah uji T dan Uji F.
Untuk mengetahui tingkat ignifikan pengaruh variabel bebas ecara simultan terhadap variabel terikat digunakan uji F. Hasil yang diperoleh adalah sebagai berikut :

Tabel 1 ANOVA

\begin{tabular}{|l|r|r|r|r|r|}
\hline \multicolumn{7}{|c|}{ ANOVA } \\
\hline Model & $\begin{array}{c}\text { Sum of } \\
\text { Squares }\end{array}$ & df & $\begin{array}{c}\text { Mean } \\
\text { Square }\end{array}$ & F & Sig. \\
\hline 1 Regression & 1154,390 & 3 & 384,797 & 68,121 &, $000^{D}$ \\
\hline Residual & 293,735 & 52 & 5,649 & & \\
\hline Total & 1448,125 & 55 & & & \\
\hline a. Dependent Variable: $(0)$ & & & \\
\hline b. Predictors: (Constant), $(\times 3),(\times 1),(\times 2)$ & \\
\hline
\end{tabular}

Sumber : data primer diolah, 2016 Hipotesis :

HO :variabel kemampuan,
pengalaman dan disiplin
tidak berpengaruh
signifikan secara simultan
terhadap
kinerjaforextrader. H1 :variabel kemampuan, pengalaman dan disiplin berpengaruh signifikan secara simultan terhadap kinerjaforextrader.

Dasar pengambilan keputusan : Jika probabilitas (sig)> 0,05 atau nilai $\mathrm{F}$ hitung $<\mathrm{F}$ tabel maka $\mathrm{H} 0$ 
diterima atau $\mathrm{H} 1$ ditolakjika probabilitas $($ sig $)<0,05$ atau nilai $\mathrm{F}$ hitung $>\mathrm{F}$ tabel maka $\mathrm{H} 0$ ditolak atau $\mathrm{H} 1$ diterima.

Keputusan :

Berdasarkan tabel diatas, diketahui bahwa koefisien uji Fhitung diperoleh sebesar 68,121dengan nilai $\mathrm{F}_{\text {tabel }}$ pada tingkat kepercayaan 95\% atau $\alpha=0,05$ dengan derajat kebebasan diketahui 2,78, serta nilai probabilitas signifikan 0,000. Maka perhitungan tersebut menunjukkan bahwa :

$$
\text { Fhitung 68,121> } \mathrm{F}_{\text {tabel2,78 }} \text { atau }
$$

Probabilitas (sig.) $0,000<\alpha$ 0,05

Dari hasil tersebut diketahui bahwa H0 yaitu variabel kemampuan, pengalaman dan disiplin tidak berpengaruh signifikan secara simultan terhadap kinerjaforextrader ditolak, maka H1 yaitu variabel kemampuan, pengalaman dan disiplin berpengaruh signifikan secara simultan terhadap kinerjaforextrader diterima. Artinya terdapat hubungan linier antara kemampuan, pengalaman, disiplin dan kinerja.
Untuk mengetahui tingkat signifikan pengaruh variabel bebas secara parsial terhadap variabel terikat digunakan uji T. Hasil yang diperoleh adalah sebagai berikut :

Tabel Coefficients

\begin{tabular}{|c|c|c|c|c|c|}
\hline \multicolumn{6}{|c|}{ Coefficients ${ }^{\mathrm{a}}$} \\
\hline \multirow[b]{2}{*}{ Model } & \multicolumn{2}{|c|}{$\begin{array}{l}\text { Unstan dar dized } \\
\text { Coefficients }\end{array}$} & \multirow{2}{*}{$\begin{array}{c}\text { Standardized } \\
\text { Coefficients } \\
\text { Beta }\end{array}$} & \multirow[b]{2}{*}{$t$} & \multirow[b]{2}{*}{ Sig. } \\
\hline & B & $\begin{array}{l}\text { Std. } \\
\text { Error }\end{array}$ & & & \\
\hline 1 (Constant) & 2,736 & 1,119 & & 2,445 &, 08 \\
\hline$(x 1)$ & , 188 & ,062 & ,276 & 3,025 &,$\infty 04$ \\
\hline$(x 2)$ & 265 & ,090 & 289, & 2,943 &, 05 \\
\hline$(3)$ & 454 & ,089 & 447 & 5,098 &, 000 \\
\hline
\end{tabular}

Sumber : data primer diolah, 2016

Untuk menguji hipotesis dari masing-masing variabel bebas maka pengujian hipotesis dilakukan terpisah, berikut adalah hasilnya :

1) Variabel Kemampuan $(\mathrm{X} 1)$

Hipotesis :

H0 : Variabel kemampuan tidak berpengaruh signifikan terhadap Kinerja forextrader.

H1 : Variabel kemampuan berpengaruh signifikan terhadap Kinerja forextrader.

Dasar pengambilan keputusan :

Jika probabilitas (sig)> 0,05

atau nilai $T_{\text {hitung }}<\mathrm{T}_{\text {tabel }}$ maka $\mathrm{H} 0$ 
diterima atau $\mathrm{H} 1$ ditolakjika probabilitas $(\mathrm{sig})<0,05$ atau nilai $\mathrm{T}_{\text {hitung }}>\mathrm{T}_{\text {tabel }}$ maka $\mathrm{H} 0$ ditolak atau H1 diterima.

Keputusan :

Berdasarkan tabel diatas, diketahui bahwa koefisien uji Thitung diperoleh sebesar 3,025 dengan nilai $\mathrm{T}_{\text {tabel }}$ pada tingkat kepercayaan $95 \%$ atau $\alpha=0,05$ dengan derajat kebebasan diketahui 2,00665, serta nilai probabilitas signifikan 0,004 . Maka perhitungan tersebut menunjukkan bahwa :

Thitung3,025 $>\mathrm{T}_{\text {tabel2, }}$,00665 atau Probabilitas (sig.) 0,004 $<\alpha 0,05$

Dari hasil tersebut diketahui bahwa H0 yaitu Variabel Kemampuan tidak berpengaruh signifikan terhadap kinerja forextraderditolak, maka H1 yaitu Variabel kemampuan berpengaruh signifikan terhadap Kinerja forextraderditerima. Artinya terdapat hubungan linier antara kemampuan dan kinerja. Sedangkan besarnya pengaruhkemampuan terhadap kinerja sebesar 0.276 atau $27,6 \%$.

2) Variabel Pengalaman $(\mathrm{X} 2)$

Hipotesis :

H0 : Variabel pengalaman tidak berpengaruh signifikan terhadap Kinerja forextrader.

H1 : Variabel pengalaman berpengaruh signifikan terhadap Kinerja forextrader.

Dasar pengambilan keputusan :

Jika probabilitas (sig)> 0,05 atau nilai $\mathrm{T}_{\text {hitung }}<\mathrm{T}_{\text {tabel }}$ maka $\mathrm{H} 0$ diterima atau H1 ditolakjika probabilitas $(\mathrm{sig})<0,05$ atau nilai $\mathrm{T}_{\text {hitung }}>\mathrm{T}_{\text {tabel }}$ maka H0 ditolak atau H1 diterima.

Keputusan :

Berdasarkan tabel diatas, diketahui bahwa koefisien uji Thitung diperoleh sebesar 2,943 dengan nilai $\mathrm{T}_{\text {tabel }}$ pada tingkat kepercayaan 95\% atau $\alpha=0,05$ dengan derajat kebebasan diketahui 2,00665, serta nilai probabilitas signifikan 0,005. Maka perhitungan tersebut menunjukkan bahwa : 
Thitung2,943 $>\mathrm{T}_{\text {tabel2,00665 }}$ atau

Probabilitas (sig.) 0,005 $<\alpha$ 0,05

Dari hasil tersebut diketahui bahwa H0 yaitu Variabel pengalaman tidak berpengaruh signifikan terhadap Kinerja forextraderditolak, maka H1 yaitu Variabel pengalaman berpengaruh signifikan terhadap Kinerja forextraderditerima. Artinya terdapat hubungan linier antara pengalaman dan kinerja. Sedangkan besarnya pengaruh pengalaman terhadap kinerja sebesar 0.289 atau $28,9 \%$.

3) Variabel Disiplin (X3)

Hipotesis :

HO : Variabel disiplin tidak berpengaruh signifikan terhadap Kinerja forextrader.

H1 : Variabel disiplin berpengaruh signifikan terhadap Kinerja forextrader.

Dasar pengambilan keputusan :

Jika probabilitas (sig)> 0,05 atau nilai $T_{\text {hitung }}<\mathrm{T}_{\text {tabel }}$ maka $\mathrm{H} 0$ diterima atau $\mathrm{H} 1$ ditolakjika probabilitas $(\mathrm{sig})<0,05$ atau nilai $\mathrm{T}_{\text {hitung }}>\mathrm{T}_{\text {tabel }}$ maka $\mathrm{H} 0$ ditolak atau H1 diterima.
Keputusan :

Berdasarkan tabel diatas, diketahui bahwa koefisien uji Thitung diperoleh sebesar 5,093 dengan nilai $\mathrm{T}_{\text {tabel }}$ pada tingkat kepercayaan 95\% atau $\alpha=0,05$ dengan derajat kebebasan diketahui 2,00665, serta nilai probabilitas signifikan 0,000 . Maka perhitungan tersebut menunjukkan bahwa :

Thitung5,093 > $\mathrm{T}_{\text {tabel2,00665 atau }}$

Probabilitas (sig.) $0,000<\alpha 0,05$

Dari hasil tersebut diketahui bahwa H0 yaitu Variabel disiplin tidak berpengaruh signifikan terhadap Kinerja forextraderditolak, maka H1 yaitu Variabel disiplin berpengaruh signifikan terhadap Kinerja forextraderditerima. Artinya terdapat hubungan linier antara disiplin dan kinerja. Sedangkan besarnya pengaruh disiplin terhadap kinerja sebesar 0.447 atau $44,7 \%$. 
Selain dari hasil uji $\mathrm{T}$ di atas, pada tabel 5.14 juga dapat diketahui persamaan regresi adalah :

$Y=2,736+0,188 X 1+0,265 X 2+$ $0,454 X 3$

Keterangan :

$\mathrm{Y}=$ Kinerja

$\mathrm{X} 1=$ Kemampuan

X2 = Pengalaman

X3 = Disiplin

Berdasarkan persamaan yang diperoleh pada variabel kemampuan nilai b 0,188, signifikan sebesar 0,004 , variabel pengalaman nilai $b$ 0,265 serta nilai signifikan sebesar 0,005 , dan variabel disiplin nilai $b$ 0,454 serta nilai signifikan 0,000 .

Dengan demikian dapat diketahui apabila nilai variabel kemampuan, pengalaman dan disiplin bernilai 0 maka kinerja bernilai 2,736 dan apabila nilai variabel kemampuan naik satusatuan maka variabel kinerja naik sebesar 0,188 satuan, apabila variabel pengalaman naik satusatuan maka variabel kinerja naik sebesar 0,265 satuan, serta apabila variabel disiplin naik satu-satuan maka variabel kinerja naik sebesar 0,454 satuan. Dari hasil tersebut dapat diketahui bahwa variabel disiplin yang paling berpengaruh signifikan terhadap kinerja disusul dengan variabel pengalaman lalu variabel kemampuan.

\section{KESIMPULAN}

Adapun simpulan yang dapat di ambil dari hasil penelitian dan pembahasan adalah sebagai berikut:

1) Variabel kemampuan memperoleh hasil thitung lebih besar daripada tabel yaitu 3,025 $>2,00665$ dengan signifikan 0,004 < 0,05, disimpulkan bahwa kemampuan berpengaruh positif dan signifikan terhadap kinerja forex trader di Kalimantan Selatan, sedangkan besarnya pengaruh kemampuan terhadap kinerja sebesar 0.276 atau $27,6 \%$.

2) Variabel pengalaman memperoleh hasil thitung lebih besar daripada tabel yaitu 2,943 $>2,00665$ dengan signifikan 
$0,005<0,05$, disimpulkan bahwa pengalaman berpengaruh positif dan signifikan terhadap kinerja forex trader di Kalimantan Selatan, sedangkan besarnya pengaruh pengalaman terhadap kinerja sebesar 0.289 atau $28,9 \%$.

3) Variabel disiplin memperoleh hasil thitung lebih besar daripada ttabel yaitu 5,093 >2,00665 dengan signifikan $0,000<0,05$, disimpulkan bahwa disiplin berpengaruh positif dan signifikan terhadap kinerja forex trader di Kalimantan Selatan, sedangkan besarnya pengaruh disiplin terhadap kinerja sebesar 0.447 atau $44,7 \%$.

variabelkemampuan, pengalaman dan disiplin secara bersama-sama memperoleh Fhitung lebih besar daripada Ftabelyaitu 68,121 > 2,78 dengan signifikansi $0,000<0,05$, disimpulkan bahwa kemampuan, pengalaman dan disiplin secara bersama-sama berpengaruh positif dan signifikan terhadap kinerja forex trader di Kalimantan Selatan.

\section{SARAN}

Berdasarkan kesimpulan diatas dan hasil penelitian yang dilakukan peneliti, terdapat beberapa hal yang perlu diperhatikan oleh trader antara lain :

1) Perlunya meningkatkan Disiplin karena disiplin paling berpengaruh terhadap kinerja, dengan meningkatkan disiplin maka kinerja seorang trader akan meningkat. Disiplin yang ditingkatkan berupa pengaturan risk pada saat melakukan order. Risk disesuaikan dengan resiko kerugian yang siap diterima oleh trader.

2) Untuk meningkatkan kinerja faktor pengalaman tak kalah penting, trader dihimbau untuk meningkatkan jam terbang, meningkatkan pengetahuan tentang analisis fundamental dan teknikal, serta selalu menggunakan risk yang kecil sehingga Margin Call bisa dihindari.

3) Kemampuan mengendalikan emosi saat melakukan 


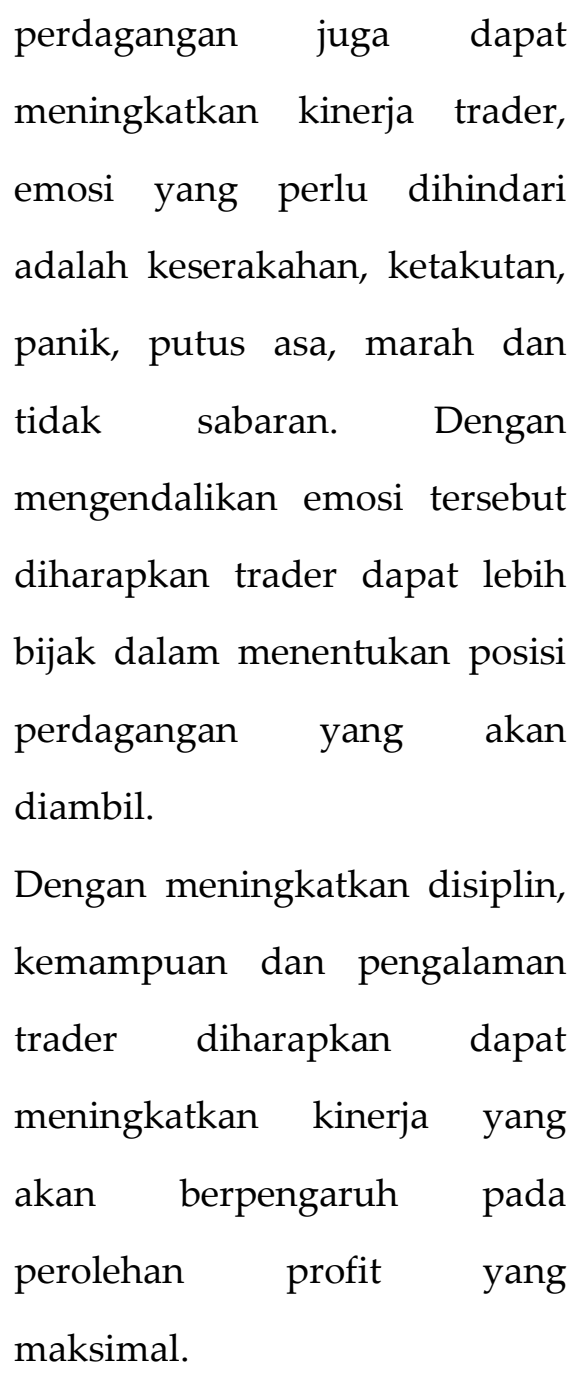

\section{DAFTAR PUSTAKA}

Abdurrahman Fathoni, 2006, Manajemen Sumber Daya Manusia, Bandung : Rineka Cipta.

Anwar Prabu Mangkunegara. 2005. Evaluasi Kinerja, Bandung : Refika Aditama.

Anwar Prabu Mangkunegara. 2011, Manajemen Sumber Daya Manusia Perusahaan, Bandung
Arikunto, S., 2006. Prosedur Penelitian Suatu Pendekatan Praktik. Jakarta: Rineka Cipta. : PT Remaja Rosdakarya.

As'ad, 2000. Psikologi Industri. Ed 4, Yogjakarta : Liberty.

Barry Cushway, 2002, Human Resource Management, Jakarta : PT. Alex Media Kumputindo.

Elaine B Johnson PH.D, 2007, Contextual Teaching and Learning, Bandung, MLC.

Eti Rochaety dkk. 2005. Sistem Informasi Manajemen pendidikan, Jakarta : Bumi Aksara

Fudin Zainal Abidin, 2013, Pengaruh Disiplin terhadap Kinerja Karyawan pada PT. Rekatama Putra Gegana Bandung, Universitas Winaya Mukti, Bandung.

Ghozali, Imam, 2006, Aplikasi Analisis Multivariate dengan Program SPSS, Cetakan Keempat, Badan Penerbit Universitas Diponegoro, Semarang

Hariandja. Marihot T.E. 2002. Manajemen Sumber Daya Manusia, Jakarta, : Grasindo. 
Hasibuan , Malayu S.P. 2002. Manajemen Sumber Daya Manusia. Jakarta : Bumi Aksara.

Hayuzza, Angelique. 2006, faktorfaktor analisis yang berpengaruh terhadap pengambilan keputusan dalam Transaksi Forex di perdagangan berjangka, Universitas Widyatama, Bandung.

Ika Rahmatika, 2014, pengaruh kemampuan dan motivasi kerja Terhadap kinerja karyawan, Uin Syarif Hidayatullah, Jakarta.

Kristiani, Diah Ayu, Ari Pradhanawati, Ari M.S dan Wijayanto, Andi, 2013, Pengaruh Kemampuan Kerja dan Motivasi Kerja Terhadap Kinerja Karyawan (Studi pada Karyawan Operator PT. Indonesia Power Unit Bisnis Pembangkitan Semarang), Diponegoro journal Of Social and Politic.

Lulud Suci Maharini, 2011, Pengaruh Analisis Fundamental Dan Teknikal Terhadap Pengambilan Keputusan Dalam Transaksi Forex Pada Perdagangan Berjangka, universitas islam negeri Maulana malik ibrahim, Malang.

Miftah Thoha. 2007. Kepemimpinan dalam Manajemen. Edisi 12, Jakarta : PT. Raja Grafindo Persada.
Moh. Nazir, 2003, Metode Penelitian, Cetakan Kelima, Jakarta, Ghalia Indonesia.

Robbins, Stephen P., 2006. Perilaku Organisasi, PT Indeks, Kelompok Gramedia, Jakarta.

Saka Yulius, 2014, Pengaruh Kemampuan Dan Motivasi Terhadap Kinerja Pegawai Bagian Sekretariat Di Dinas Pekerjaan Umum Provinsi Bengkulu,Universitas Bengkulu, Bengkulu.

Santoso, Singgih, 2010, Statistik Multivariat, Jakarta:PT Elex Media Komputindo,

Sedarmayanti, 2011, Manajemen Sumber Daya Manusia, reformasi birokrasidan manajemen pegawai negeri sipil cetakan kelima, Bandung, PT. Refika Aditama

Srini Poerwati, 2003, Pengaruh pengalaman terhadap Kinerja dan Kepuasan Kerja : Profesionalisme sebagai variabel intervening, Universitas Diponegoro,Semarang.

Sugiyono. 2013, Metode Penelitian Kuantitatif Kualitatif dan $R \mathcal{E} D$, , Bandung Alfabeta. 
Soekanto, Soerjono. 2000. Sosiologi Suatu Pengantar. Jakarta: PT Raja Grafindo Persada.

Stephen P Robbins, 2001, Perilaku Organisasi: Konsep, Kontrversi, Aplikasi Penerjemah Hadyana Pujaatmaka dkk, Jakarta: Prehallindo.

Uma Sekaran, 2006, Metodologi Penelitian untuk Bisnis, Edisi 4, Buku 1, Jakarta: Salemba Empat.

Uma Sekaran, 2006, Metodologi Penelitian untuk Bisnis, Edisi 4, Buku 2, Jakarta: Salemba Empat. 